Article

\title{
Long-Term Survival and Recurrence in Oropharyngeal Squamous Cell Carcinoma in Relation to Subsites, HPV, and p16-Status
}

\author{
Malin Wendt 1,*iD, Lalle Hammarstedt-Nordenvall 1,2, Mark Zupancic ${ }^{2,3}$, Signe Friesland ${ }^{2,3}$, David Landin ${ }^{1}$, \\ Eva Munck-Wikland 1,2, Tina Dalianis ${ }^{2,3}$, Anders Näsman ${ }^{3,4,+}$ (D) and Linda Marklund 1,2, \\ 1 Department of Clinical Science, Intervention and Technology-CLINTEC Division of Ear, \\ Nose and Throat Diseases, Karolinska Institutet, Karolinska University Hospital, 17164 Stockholm, Sweden; \\ Lalle.Hammarstedt-Nordenvall@sll.se (L.H.-N.); David.Landin@ki.se (D.L.); \\ Eva.Munck-Wikland@ki.se (E.M.-W.); Linda.Marklund@ki.se (L.M.) \\ 2 Medical Unit Head Neck, Lung and Skin Cancer, Karolinska University Hospital, 17176 Stockholm, Sweden; \\ Mark.Zupancic@ki.se (M.Z.); signe.friesland@sll.se (S.F.); Tina.Dalianis@ki.se (T.D.) \\ 3 Department of Oncology-Pathology, Karolinska Institutet, Bioclinicum J6:20, Karolinska University Hospital, \\ 17164 Stockholm, Sweden; Anders.Nasman@ki.se \\ 4 Department of Clinical Pathology, CCK R8:02, Karolinska University Hospital, 17164 Stockholm, Sweden \\ * Correspondence: Anna.Malin.Wendt@ki.se \\ + Authors contributed equally to this work.
}

Citation: Wendt, M.; Hammarstedt-Nordenvall, L.; Zupancic, M.; Friesland, S.; Landin, D.; Munck-Wikland, E.; Dalianis, T.; Näsman, A.;

Marklund, L. Long-Term Survival and Recurrence in Oropharyngeal Squamous Cell Carcinoma in Relation to Subsites, HPV, and p16-Status. Cancers 2021, 13, 2553. https:/ / doi.org/10.3390/cancers13112553

Academic Editor: Heather Walline

Received: 28 April 2021

Accepted: 19 May 2021

Published: 23 May 2021

Publisher's Note: MDPI stays neutral with regard to jurisdictional claims in published maps and institutional affiliations.

Copyright: (c) 2021 by the authors. Licensee MDPI, Basel, Switzerland. This article is an open access article distributed under the terms and conditions of the Creative Commons Attribution (CC BY) license (https:// creativecommons.org/licenses/by/ $4.0 /)$.
Simple Summary: Long-term survival in patients with oropharyngeal cancer is sparsely studied, but atypical recurrences in human papillomavirus-positive (HPV+) oropharyngeal cancer have been indicated. Furthermore, while the role of HPV is well established in tonsillar and base of tongue cancer, the dominant oropharyngeal subsites, its role in the minor oropharyngeal sites (the oropharyngeal walls, the uvula, and the soft palate) is not fully elucidated. The aim of this retrospective study was therefore to assess long-term outcome in relation to oropharyngeal sub-sites and $\mathrm{HPV} / \mathrm{p} 16$ status. We confirm the prognostic role of p16+ in tonsillar and base of tongue cancer, but not the other sites. We find that combined HPV/p16-status gives better prognostic information than p16 alone. Lastly, we show that p16- cancer has more locoregional and late recurrences compared to $\mathrm{p} 16+$ cancer. Consequently, only combined HPV/p16 positivity in patients with tonsillar and tongue base cancer should be used in future treatment de-escalation trials.

Abstract: Long-term survival data in relation to sub-sites, human papillomavirus (HPV), and $\mathrm{p} 16^{\mathrm{INK} 4 \mathrm{a}}$ (p16) for patients with oropharyngeal squamous cell carcinoma (OPSCC) is still sparse. Furthermore, reports have indicated atypical and late recurrences for patients with HPV and p16 positive OPSCC. Therefore, we assessed long-term survival and recurrence in relation to oropharyngeal subsite and HPV/p16 status. A total of 529 patients with OPSCC, diagnosed in the period 2000-2010, with known HPVDNA and p16-status, were included. HPV/p16 status and sub-sites were correlated to disease-free and overall survival (DFS and OS respectively). The overexpression of p16 $\left(\mathrm{p} 16^{+}\right)$is associated with significantly better long-term OS and DFS in tonsillar and base of tongue carcinomas (TSCC/BOTSCC), but not in patients with other OPSCC. Patients with HPVDNA ${ }^{+} / \mathrm{p}^{+} 6^{+}$ TSCC/BOTSCC presented better OS and DFS compared to those with HPVDNA ${ }^{-} / \mathrm{p}^{16^{-}}$tumors, while those with $\mathrm{HPVDNA}^{-} / \mathrm{p}^{+} 6^{+}$cancer had an intermediate survival. Late recurrences were rare, and significantly more frequent in patients with $\mathrm{p} 16^{-}$tumors, while the prognosis after relapse was poor independent of HPVDNA ${ }^{+/-} / \mathrm{p} 16^{+/-}$status. In conclusion, patients with $\mathrm{p}^{+} 6^{+} \mathrm{OPSCC}$ do not have more late recurrences than $\mathrm{p} 16^{-}$, and a clear prognostic value of $\mathrm{p} 16^{+}$was only observed in TSCC/BOTSCC. Finally, the combination of HPVDNA and p16 provided superior prognostic information compared to p16 alone in TSCC/BOTSCC.

Keywords: human papillomavirus; HPV; oropharyngeal cancer; OPSCC; tonsillar cancer; survival; OS; DFS; p16; recurrence 


\section{Introduction}

Already in 1983, Syrjänen et al. suggested a possible correlation between human papillomavirus (HPV) infection and head and neck squamous cell carcinoma (HNSCC) [1]. In the following decades, extensive research, by ourselves and others, established highrisk HPV infection as a risk factor of oropharyngeal squamous cell carcinoma (OPSCC), and especially tonsillar and base of tongue cancer (TSCC and BOTSCC) [2-7]. Data also showed that patients with HPV positive OPSCC, more specifically HPV positive TSCC and BOTSCC, had a better clinical outcome, as well as a different epidemiological profile, when compared to patients with corresponding HPV negative cancer [8-10]. More specifically, the incidence of HPV positive TSCC and BOTSCC, and thereby OPSCC, has continuously increased in the Western world since the 1970's, and this increase has been described as an epidemic of viral induced OPSCC, or more specifically, TSCC and BOTSCC [5,11,12]. At the same time, the prevalence of smoking has decreased, resulting in a parallel decrease in the total incidence of HNSCC, but with a shift towards a larger proportion of HPV positive tumors in the oropharyngeal subsites [11].

The overexpression of $\mathrm{p} 16^{\text {Ink4a }}\left(\mathrm{p} 16^{+}\right)$has, similar to the presence of HPV-DNA $\left(\mathrm{HPVDNA}^{+}\right)$, been shown to have a strong correlation to active HPV infection (i.e., expression of HPV E6 mRNA) in OPSCC, although the combined presence of both $\mathrm{p} 16^{+}$ and HPVDNA ${ }^{+}$is superior to using these markers separately [13]. Because $16^{+}$is easier to determine by immunohistochemistry (IHC), it was therefore suggested as a possible surrogate marker for HPV infection, and thereby also shown to be associated with a better prognosis in OPSCC $[14,15]$. In addition, $\mathrm{p} 16^{+}$as a marker of HPV infection is now used in the 8th version of the American Joint Committee of Cancer (AJCC) AJCC Staging manual (TNM-8) to separate HPV-related from HPV-unrelated OPSCC [16].

However, recent studies, by ourselves and others, have suggested that the prevalence of HPV infection, its correlation to $\mathrm{p} 16^{+}$, and the impact of HPV infection on prognosis differs considerably between OPSCC sites. More specifically, the role of HPV on survival differs between tumors arising in lymphoepithelial oropharyngeal sites, i.e., TSCC and BOTSCC, and carcinomas arising in non-lymphoepithelial subsites of the oropharynx, i.e., carcinomas of the soft palate, uvula, and posterior pharyngeal wall (otherOPSCC) [17]. Therefore, while the prognostic role of HPV and the correlation between HPV infection and $\mathrm{p} 16^{+}$is established in TSCC and BOTSCC, the role of HPV and its correlation to $\mathrm{p} 16^{+}$ in otherOPSCC is more ambiguous [18-24].

Irrespectively, roughly $10-20 \%$ of all patients with $\mathrm{p} 16^{+}$or HPVDNA ${ }^{+}$OPSCC develop recurrent disease within 5 years after diagnosis $[25,26]$. Moreover, previous observations have proposed that patients with $\mathrm{p}^{1} 6^{+}$or $\mathrm{HPVDNA}^{+}$OPSCC exhibit a different pattern of recurrence compared to those with corresponding $\mathrm{p} 16^{-}$or HPVDNA ${ }^{-}$OPSCC $[27,28]$. It has specifically been indicated that the former group presents later recurrences and at different sites, compared to the latter, an issue that needs further study $[29,30]$.

The aim of the present study was therefore to accumulate more knowledge regarding long-term survival, and recurrence in patients with OPSCC in relation to $\mathrm{p} 16^{+}$and $\mathrm{HPVDNA}^{+}$status and OPSCC subsite.

\section{Materials and Methods}

\subsection{Patients' Characteristics}

All patients diagnosed in the period 2000-2010 with OPSCC, (TSCC: ICD-10 C09.09 and C02.4; BOTSCC C01.9; otherOPSCC: C10.0-9, C05.1-9), in the County of Stockholm/Gotland, Sweden were identified through the Swedish Cancer Registry. Patients treated with palliative intent were excluded from further studies. In addition, patients diagnosed with only cytology and/or with unknown p16 status, or there were no biopsies available, were also excluded $(n=25)$, and of these, 4 patients had a recurrence: 3 locoregional relapse (LRR) and 1 distant relapse (DR). Consequently, the study base consisted of 529 OPSCC patients, treated with the intention to cure and with known p16 and HPV DNA status (see below). 
Patients' charts were assessed for TNM 7-stage, age, gender, smoking, WHO-status, type of treatment, recurrence, time to recurrence and location of recurrence, and survival. Treatment was classified as surgery, radiotherapy (including both external and brachytherapy), or chemoradiotherapy. Smoking data was obtained whenever noted in the charts, and was classified as "never" smoker or as "ever" smoker. The study was conducted according to ethical permissions 2005/431-31/4, 2005/1330-32 and 2009/1278-31/2 from the Stockholm Regional Ethical Review Board.

\section{2. $H P V-D N A$ and Overexpression of $p 16$}

Data on HPV DNA status and p16 status were obtained from previous studies [19,31]. Briefly, DNA was extracted from pre-treatment FFPE biopsies and analyzed for the presence of HPV DNA by PCR using broad-spectrum general primers bsGP5+/6+, and HPV-typing was performed utilizing a bead based multiplex assay (Luminex Magpix; Austin, TX, USA). For details, see $[19,31]$.

Likewise, data on $\mathrm{p} 16^{\text {Ink4a }}$ overexpression by immunohistochemistry was obtained from previous studies [18,32]. Overexpression of $\mathrm{p} 16\left(\mathrm{p} 16^{+}\right)$was defined as a strong nuclear and cytoplasmatic staining in more than $70 \%$ of tumor cells, as suggested by the College of American Pathologists [33].

\subsection{Statistical and Survival Analysis}

To evaluate differences in categorical data, we used a Chi- ${ }^{2}$ test; for the continuous variables we used an independent two-tailed $t$-test.

Overall survival (OS) was defined as time from diagnosis until death of any cause. Disease-free survival (DFS) was defined as time from diagnosis until recurrence of disease. A patient was considered to have recurrence of disease when treatment with curative intent was completed, patient was assessed as complete response at check-up, and then having a recurrence confirmed by radiology and/or histopathology. Recurrence was classified as LRR if in T- or N-position, and DR in M-position. Time-to recurrence was calculated as time from diagnosis until confirmed recurrence was noted in the patient chart. Patients who died tumor-free were censored at the time of death. Patients that never became tumor-free after treatment were censored at day 0 . All patients had clinical controls every 3 months for the first 2 years, then every 6 months for a total of 5 years, and then if patients showed symptoms. In the case of recurrent disease, patients started clinical controls according to the same schedule after treatment.

OS and DFS was calculated for the whole OPSCC group, as well as for TSCC/BOTSCC and otherOPSCC separately, in relation to p16. Outcome was set as death of any cause or recurrence (LRR or DR). Results were presented in Kaplan-Meier curves, and survival was assessed with a log-rank test.

A sub-group analysis with univariate and multivariate analyzes was performed in patients with TSCC/BOTSCC and performance status (WHO/ECOG) (PS) 0 as a proxy for capacity to fulfill treatment. Here, hazard ratios (HR) for the combinations of $\mathrm{HPVDNA}^{+/-} / \mathrm{p} 16^{+/-}$status, age, stage, and smoking were estimated using the Cox proportional hazard model.

All analyses were made in SPSS (version 25 for Mac); $p$-values of $<0.05$ were considered significant.

\section{Results}

\subsection{Patient and Tumor Characteristics}

All patients at baseline, and their tumor characteristics, are depicted in Table 1 . The largest proportion of primary tumors were TSCC (63\%) and BOTSCC (22\%), followed by otherOPSCC (15\%). Patients with TSCC and BOTSCC (TSCC/BOTSCC) were younger at diagnosis compared to otherOPSCC (60.8 vs. 65.2 years, $p=0.01)$, and were diagnosed with a more advanced N-status (N0-1 vs. N2-3, $p=0.01$ ). 
Table 1. Patient and tumor characteristics.

\begin{tabular}{|c|c|c|c|c|c|}
\hline & & $\operatorname{TSCC}(\%)$ & $\begin{array}{c}\text { BOTSCC } \\
(\%)\end{array}$ & $\begin{array}{c}\text { OtherOPSCC } \\
(\%)\end{array}$ & Total (\%) \\
\hline Number of patients & & 337 & 126 & 66 & 529 \\
\hline \multirow{3}{*}{ Age } & Mean & 60.4 & 62 & 65.2 & 61 \\
\hline & Median & 59 & 62 & 65 & 61 \\
\hline & Range & $29-90$ & $30-84$ & $46-88$ & $29-90$ \\
\hline \multirow{2}{*}{ Sex } & Female & $82(24 \%)$ & $39(31 \%)$ & $23(35 \%)$ & $144(27 \%)$ \\
\hline & Male & $255(76 \%)$ & $87(69 \%)$ & $43(65 \%)$ & $385(73 \%)$ \\
\hline $\mathrm{T}$ & $\mathrm{T} 1$ & $78(23 \%)$ & $40(32 \%)$ & $8(12 \%)$ & $126(24 \%)$ \\
\hline \multirow[t]{4}{*}{ (AJCC 7th Edition) } & $\mathrm{T} 2$ & $129(38 \%)$ & $33(26 \%)$ & $24(36 \%)$ & $186(35 \%)$ \\
\hline & T3 & $70(21 \%)$ & $17(13 \%)$ & $25(38 \%)$ & $112(21 \%)$ \\
\hline & T4a & $56(17 \%)$ & $36(29 \%)$ & $7(11 \%)$ & $99(19 \%)$ \\
\hline & $\mathrm{T} 4 \mathrm{~b}$ & $4(1 \%)$ & $0(0 \%)$ & $2(3 \%)$ & $6(1 \%)$ \\
\hline $\mathrm{N}$ & No & $70(21 \%)$ & $28(22 \%)$ & $29(44 \%)$ & $127(24 \%)$ \\
\hline \multirow[t]{6}{*}{ (AJCC 7th Edition) } & N1 & $72(21 \%)$ & $16(13 \%)$ & $12(18 \%)$ & $100(19 \%)$ \\
\hline & $\mathrm{N} 2 \mathrm{a}$ & $49(15 \%)$ & $13(10 \%)$ & $4(6 \%)$ & $66(12 \%)$ \\
\hline & $\mathrm{N} 2 \mathrm{~b}$ & $112(33 \%)$ & $32(25 \%)$ & $9(14 \%)$ & $153(29 \%)$ \\
\hline & $\mathrm{N} 2 \mathrm{c}$ & $21(6 \%)$ & $27(21 \%)$ & $11(17 \%)$ & $59(11 \%)$ \\
\hline & N3 & $13(4 \%)$ & $7(6 \%)$ & $1(2 \%)$ & $21(4 \%)$ \\
\hline & NX & $0(0 \%)$ & $3(2 \%)$ & $1(2 \%)$ & $3(1 \%)$ \\
\hline $\mathrm{M}$ & M0 & $335(99 \%)$ & $120(95 \%)$ & $63(95 \%)$ & $518(98 \%)$ \\
\hline \multirow[t]{2}{*}{ (AJCC 7th Edition) } & M1 & $2(1 \%)$ & $2(2 \%)$ & $0(0 \%)$ & $4(1 \%)$ \\
\hline & MX & $0(0 \%)$ & $4(3 \%)$ & $3(5 \%)$ & $7(1 \%)$ \\
\hline TNM Stage & I & $10(3 \%)$ & $8(6 \%)$ & $3(21 \%)$ & $21(4 \%)$ \\
\hline \multirow{5}{*}{ (AJCC 7th Edition) } & II & $25(7 \%)$ & $7(6 \%)$ & $12(21 \%)$ & $44(8 \%)$ \\
\hline & III & $83(25 \%)$ & $20(16 \%)$ & $23(15 \%)$ & $126(24 \%)$ \\
\hline & IVa & $198(59 \%)$ & $82(65 \%)$ & $25(33 \%)$ & $305(58 \%)$ \\
\hline & $\mathrm{IVb}$ & $19(6 \%)$ & $7(6 \%)$ & $3(6 \%)$ & $29(5 \%)$ \\
\hline & IVc & $2(1 \%)$ & $2(2 \%)$ & $0(4 \%)$ & $4(1 \%)$ \\
\hline \multirow{3}{*}{ Smoking } & Ever & $237(70 \%)$ & $79(63 \%)$ & $51(77 \%)$ & $367(69 \%)$ \\
\hline & Never & $92(27 \%)$ & $43(34 \%)$ & $7(11 \%)$ & $142(27 \%)$ \\
\hline & Not known & $8(2 \%)$ & $4(3 \%)$ & $4(6 \%)$ & $20(4 \%)$ \\
\hline \multirow[t]{2}{*}{ p16 overexpression } & No & $81(24 \%)$ & $41(33 \%)$ & $60(91 \%)$ & $182(34 \%)$ \\
\hline & Yes & $256(76 \%)$ & $85(67 \%)$ & $6(9 \%)$ & $347(66 \%)$ \\
\hline \multirow[t]{3}{*}{ HPV DNA status } & Negative & $78(23 \%)$ & $39(31 \%)$ & $47(71 \%)$ & $164(31 \%)$ \\
\hline & Positive & $259(77 \%)$ & $87(69 \%)$ & $15(23 \%)$ & $361(68 \%)$ \\
\hline & Not known & $0(0 \%)$ & $0(0 \%)$ & $4(6 \%)$ & $4(1 \%)$ \\
\hline \multirow{5}{*}{$\begin{array}{l}\text { Performance status } \\
\text { (WHO/ECOG) }\end{array}$} & 0 & $304(90 \%)$ & $102(81 \%)$ & $27(41 \%)$ & $433(82 \%)$ \\
\hline & 1 & $20(6 \%)$ & $19(15 \%)$ & $20(30 \%)$ & $59(11 \%)$ \\
\hline & 2 & $7(2 \%)$ & $5(4 \%)$ & $16(24 \%)$ & $28(5 \%)$ \\
\hline & 3 & $5(1 \%)$ & $0(0 \%)$ & $3(5 \%)$ & $8(2 \%)$ \\
\hline & Not known & $1(0 \%)$ & $0(0 \%)$ & $0(0 \%)$ & $1(0 \%)$ \\
\hline \multirow[t]{3}{*}{ Treatment ${ }^{1}$} & RT & $234(69 \%)$ & $56(44 \%)$ & $48(73 \%)$ & $340(64 \%)$ \\
\hline & CRT & $101(30 \%)$ & $70(56 \%)$ & $17(26 \%)$ & $183(35 \%)$ \\
\hline & Primary surgery & $2(1 \%)$ & $0(0 \%)$ & $4(6 \%)$ & $6(1 \%)$ \\
\hline \multirow{2}{*}{ Recurrence } & Yes & $61(18 \%)$ & $30(24 \%)$ & $19(29 \%)$ & $110(21 \%)$ \\
\hline & No & $276(82 \%)$ & $96(76 \%)$ & $47(71 \%)$ & $419(79 \%)$ \\
\hline
\end{tabular}

Neck dissection not included.

TSCC/BOTSCC were significantly more frequently $\mathrm{p} 16^{+}$and HPV $\mathrm{DNA}^{+}$, compared to otherOPSCC $\left(70.4 \%\right.$ p $16^{+}$TSCC /BOTSCC vs. $22.2 \%$ p $16^{+}$otherOPSCC, $p<0.0001$, and $72.5 \% \mathrm{HPVDNA}^{+}$TSCC/BOTSCC vs. $21 \% \mathrm{HPVDNA}^{+}$otherOPSCC, $\left.p<0.0001\right)$.

In the whole OPSCC cohort, $110 / 529$ patients $(20.8 \%)$, had recurrent disease, more specifically with $17.8 \%$ recurrences in TSCC, $24.2 \%$ in BOTSCC, and $28.8 \%$ in otherOPSCC (Table 1).

\subsection{Long-Term Overall Survival and Disease-Free Survival in Relation to $p 16$ and Subsites}

Patients with $\mathrm{p} 16^{+}$OPSCC had a significantly better OS and DFS, compared to patients with p16 ${ }^{-}$OPSCC (log rank test $<0.0001$ and $<0.0001$, respectively). More specifically, 5 year OS and DFS were $76.4 \%$ and $84.9 \%$, respectively, in patients with $16^{+}$OPSCC, and $42.4 \%$ and $64.7 \%$, respectively, in patients with p $16^{-}$OPSCC (Figure 1A,B). The 10-year OS and DFS were $65.4 \%$ and $83.7 \%$, respectively, in patients with $\mathrm{p} 16^{+}$OPSCC, and $22.9 \%$ and $59.6 \%$, respectively, in patients with p16 ${ }^{-}$OPSCC (Figure 1A,B). 


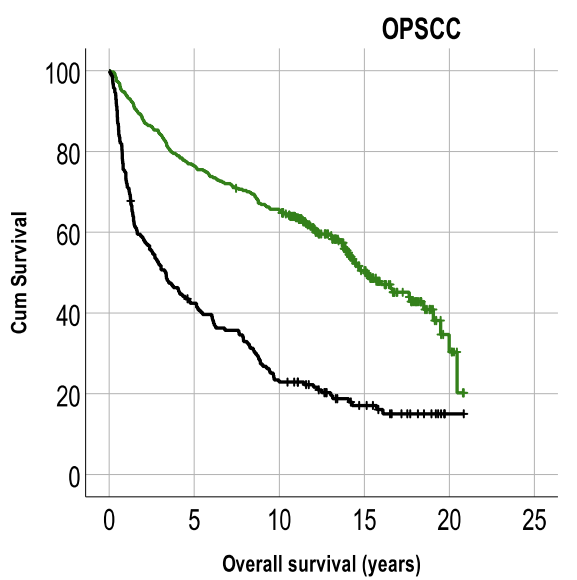

(A)

TSCC and BOTSCC

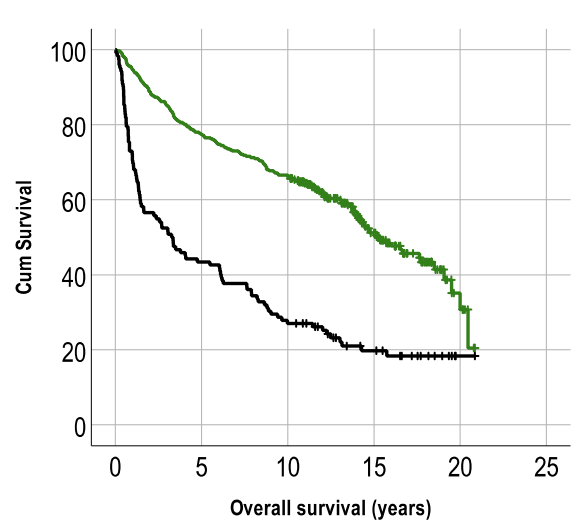

(C)

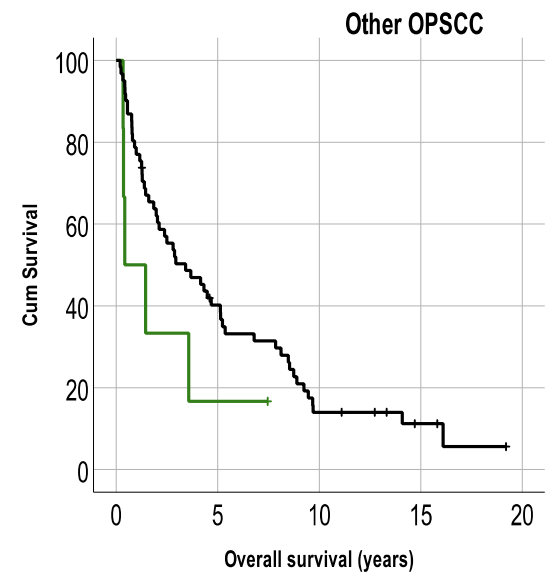

(E)

\section{p16 overexpression \\ תYes \\ $\neg$ No \\ + Yes-censored \\ +No-censored}

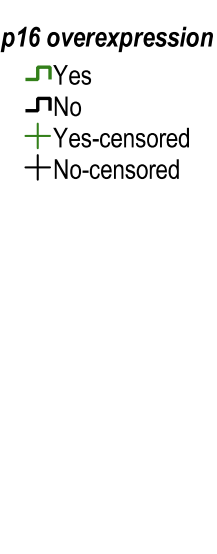

16 overexpression

$\neg$ YYes

+ Yes-censored

+No-censored

16 overexpression

$\neg Y e s$

$\neg$ NNo

+ Yes-censored

+No-censored

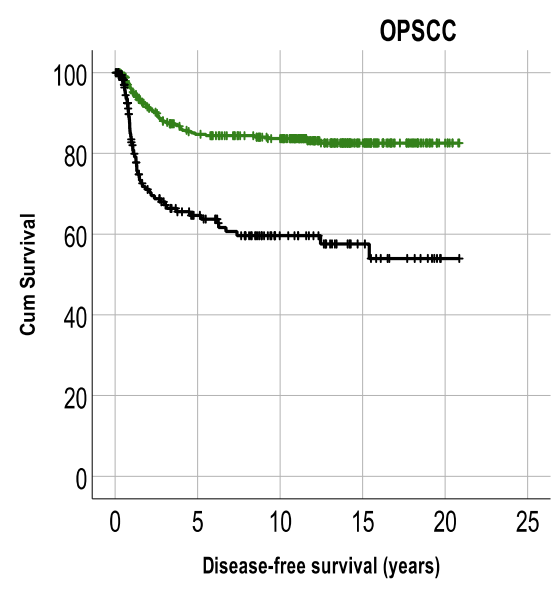

(B)

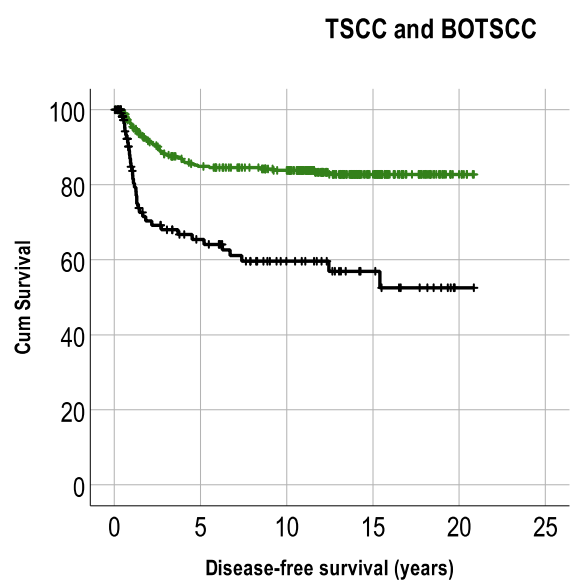

(D)

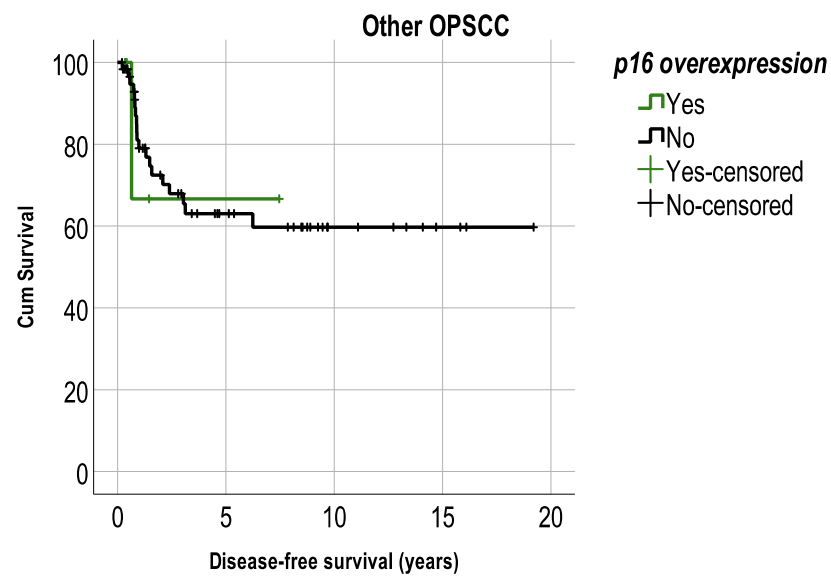

(F) p16 overexpression

$ת$ res

$\neg$ No

+ Yes-censored

+No-censored p16 overexpression

תYes

תNo

+ Yes-censored

+ No-censored

Figure 1. Kaplan-Meier figures with overall survival (OS) and disease-free survival (DFS) in patients with OPSCC (A,B) and separated on subsite with TSCC/BOTSCC $(\mathbf{C}, \mathbf{D})$ and otherOPSCC $(\mathbf{E}, \mathbf{F})$. (A,B) Patients with p16 positive OPSCC had a significantly better OS and DFS compared to patients with p16 negative OPSCC (log rank: $p<0.0001$ and $p<0.0001$, respectively). (C,F) Patients were separated into those with cancer in lymphoepithelial sub-sites (TSCC/BOTSCC) and non-lymphoepithelial subsites (otherOPSCC) and analyzed separately. (C,D) Patients with p16 positive TSCC/BOTSCC had a significantly better OS and DFS compared to patients with p16 negative TSCC/BOTSCC (log rank: $p<0.0001$ and $p<0.0001$, respectively). (E,F) No significant differences in OS and DFS between patients with p16 positive and p16 negative otherOPSCC were observed (log rank: $p=0.13$ and $p=0.9$, respectively). 
When analyzing survival per subsite, patients with $\mathrm{p} 16^{+} \mathrm{TSCC} / \mathrm{BOTSCC}$ had a significantly better OS and DFS compared to patients with $\mathrm{p} 16^{-}$TSCC/BOTSCC (log rank test $<0.0001$ and $<0.0001$, respectively). More specifically, 5-year OS and DFS were $77.4 \%$ and $84.7 \%$, respectively, in patients with $16^{+}$TSCC/BOTSCC, compared to $43.4 \%$ and $65.4 \%$, respectively, in patients with $\mathrm{p} 16^{-}$TSCC/BOTSCC. The 10 -year OS and DFS were $66.3 \%$ and $83.8 \%$, respectively, in patients with $16^{+}$TSCC/BOTSCC, compared to $27 \%$ and $59.7 \%$, respectively, in patients with p16- TSCC/BOTSCC (Figure 1C,D). Notably, few late recurrencies ( $>5$ years after diagnosis) were observed in patients with $\mathrm{p} 16^{+} \mathrm{TSCC} / \mathrm{BOTSCC}$, which was not entirely the case in patients with $\mathrm{p} 16^{-}$TSCC/BOTSCC (Figure 1D). Patients with $\mathrm{p} 16^{-}$TSCC/BOTSCC had, in fact, a significantly higher risk of having a recurrent disease five years after diagnosis, compared to patients with $\mathrm{p} 16^{+}$TSCC/BOTSCC $(p<0.001$, Figure 2).

\section{TSCC and BOTSCC}

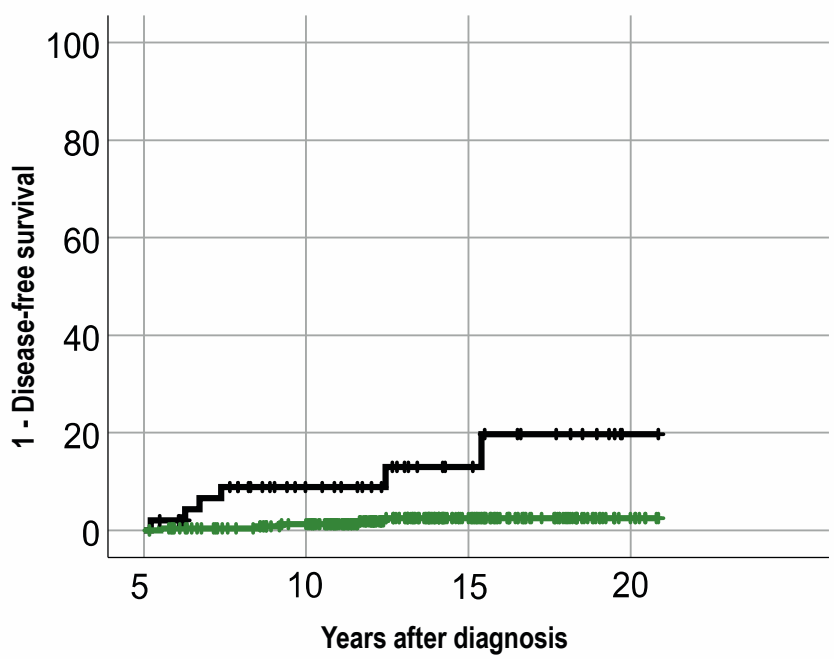

p16 overexpression $\pi$ No rYyes +No-censored +Yes-censored

Figure 2. Kaplan-Meier figure with 1-disease-free survival (DFS) in patients with TSCC/BOTSCC five years after diagnosis. Patients with 16 positive TSCC/BOTSCC had a significantly better DFS compared to patients with p16 negative TSCC/BOTSCC (log rank: $p<0.001$ ).

No differences in OS or DFS with regard to $\mathrm{p} 16^{+/-}$status were observed in patients with otherOPSCC (Figure 1E,F).

\subsection{Localisation of Recurrence and Relation to Overexpression of $p 16$ and Subsites}

Of 112 recurrences, 74 (66\%) were LRR and $38(34 \%)$ were DR. In TSCC/BOTSCC, there was an equal distribution of LRR and DR, while most otherOPSCC had LRR (Figure 3). Notably, patients with $\mathrm{p} 16^{+}$OPSCC had a significantly higher proportion of DR, compared to those with p16 ${ }^{-}$OPSCC (p16 OPSCC: Local relapse: $n=16$; Regional relapse: $n=15$; DR: $n=24$; p16- OPSCC: Local relapse: $n=37$; Regional relapse: $n=6$; DR: $n=14$ ) $(p=0.03)$. Likewise, patients with $\mathrm{p} 16^{+}$TSCC/BOTSCC tended to have more DR compared to those with $\mathrm{p} 16^{-}$TSCC/BOTSCC, while the opposite was observed in patients with otherOPSCC; however, neither of these latter trends were significant. 
- DR $\square$ LRR

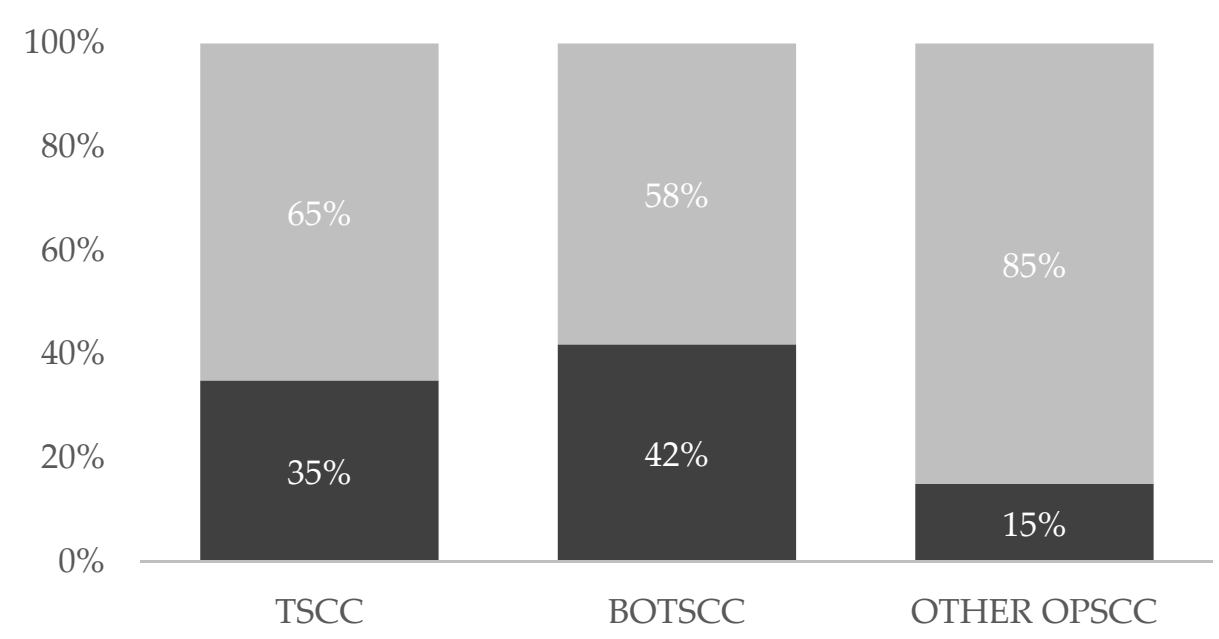

Figure 3. Distribution (percent) of loco-regional (LRR) and distant (DR) recurrencies separated per OPSCC sub-site. Patients with TSCC and BOTSCC had more often DR compared to otherOPSCC (TSCC: DR: $n=21$, LRR: $n=39$; BOTSCC: DR $n=13$, LRR $n=18$; otherOPSCC: DR $n=3$, LRR $n=17$ ).

3.4. Long-Term Overall and Disease-Free Survival in Relation to Both Overexpression of 16 and Presence of HPV DNA, in Patients with TSCC/BOTSCC

Because the prognostic role of $\mathrm{p} 16^{+}$alone was only observed in patients with TSCC/ BOTSCC, we continued our analysis by adding the presence of HPV DNA $\left(\mathrm{HPVDNA}^{+}\right)$as an additional prognostic marker, only in these tumors.

Patients with combined HPVDNA ${ }^{+} / \mathrm{p} 16^{+}$TSCC /BOTSCC had a significantly better OS and DFS compared to patients with HPVDNA ${ }^{-} / \mathrm{p}^{1} 6^{-} \mathrm{TSCC}^{-\mathrm{BOTSCC}}$ (log rank: $p<0.0001$ and $p<0.0001)$. However, patients with HPVDNA ${ }^{-} / \mathrm{p}^{16}{ }^{+}$TSCC/BOTSCC presented an intermediate survival (Figure 4A,B). More explicitly, patients with $\mathrm{HPVDNA}^{-} /$ p16 ${ }^{+}$TSCC /BOTSCC had a better OS and DFS compared to patients with HPVDNA ${ }^{-} / \mathrm{p}^{-} 6^{-}$ cancer (log rank test: $p=0.001$ and $p=0.05$, respectively), but a worse OS compared to patients with HPVDNA ${ }^{+} / \mathrm{p} 16^{+}$cancer (OS: log rank test: $p=0.047$ ), and the trend was similar for DFS (log rank test: $p=0.1$ ). Similarly, patients with HPVDNA ${ }^{+} / \mathrm{p}^{-} 6^{-}$TSCC $/$BOTSCC $(n=42)$ also presented an intermediate survival.

In more detail, 5-year OS and DFS were $78.8 \%$ and $85.9 \%$, respectively, in patients with HPVDNA ${ }^{+} / \mathrm{p} 16^{+}$TSCC/BOTSCC and $37.9 \%$ and $57.5 \%$, respectively, in patients with HPVDNA ${ }^{-} / \mathrm{p}^{-} 6^{-}$cancer. Patients with discordant HPV and p16 status presented an intermediate survival, with 63.3\% 5-year OS and 74.1\% 5-year DFS in those with $\mathrm{HPVDNA}^{-} / \mathrm{p} 16^{+}$TSCC/BOTSCC, while corresponding figures for those with HPVDNA ${ }^{+} /$ p16 ${ }^{-}$cancers were $57.1 \%$ and $85.4 \%$ for OS and DFS, respectively. Moreover, 10 -year OS and DFS were $67.8 \%$ and $85.6 \%$, respectively, in patients with $\mathrm{HPVDNA}^{+} / \mathrm{p}^{16}{ }^{+}$TSCC/BOTSCC and $11.5 \%$ and $50.9 \%$, respectively, in patients with $\mathrm{HPVDNA}^{-} / \mathrm{p}^{-} 6^{-}$cancer. Patients with discordant HPV and p16 status presented an intermediate survival, with 36.5\% 10-year OS and 74.1\% DFS in those with HPVDNA ${ }^{-} / \mathrm{p} 16^{+}$TSCC/BOTSCC, while corresponding figures for those with $\mathrm{HPVDNA}^{+} / \mathrm{p}^{-} 6^{-}$cancers were $42.9 \%$ and $80.9 \%$ for OS and DFS, respectively. 


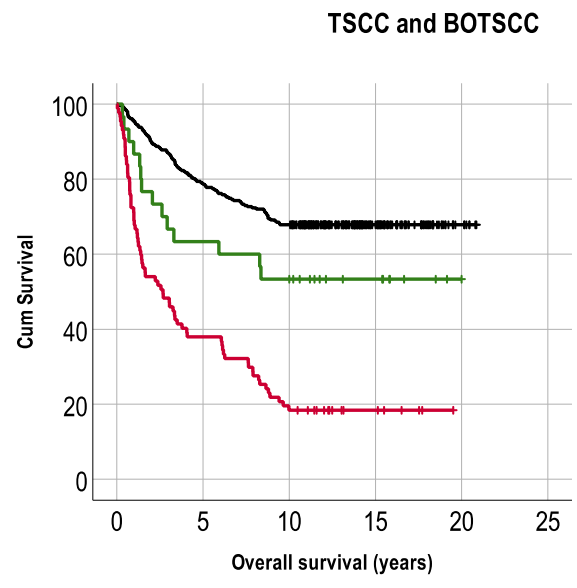

(A)

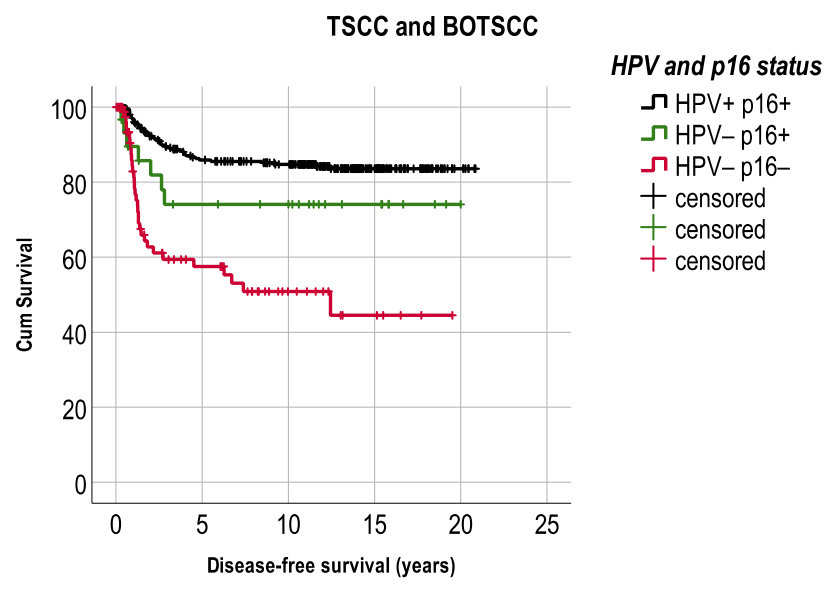

(B)

Figure 4. Kaplan-Meier figures with overall survival (OS) and disease-free survival (DFS) in patients with TSCC/BOTSCC (A,B). Patients with HPV DNA positive and p16 positive (HPV+/p16+) TSCC/BOTSCC had a significantly better OS and DFS, respectively (A,B, respectively), as compared to patients with HPV DNA negative and p16 negative TSCC/BOTSCC (log rank: $p<0.0001$ and $p<0.0001$, respectively). However, patients with p16 positive but HPV negative (HPV $-/ \mathrm{p} 16+)$ TSCC /BOTSCC presented an intermediate OS and DFS compared to patients with double positive or double negative $\mathrm{HPV} / \mathrm{p} 16$ status. (HPV+p16+ vs. HPV-p16+ (log rank test): OS: $p=0.047 ;$ DFS: $p=0.1$, and HPV - p16+vs. HPV - p16(log rank test): OS: $p=0.001$; DFS: $p=0.05)$.

\subsection{HPV, p16 Status and Other Prognostic Factors in Patients with TSCC/BOTSCC}

A univariate and multivariate subgroup analysis, including patients with TSCC/ BOTSCC and performance status (WHO/ECOG) (PS) 0, as a surrogate marker for completion of intended treatment, was performed and included $87.7 \%$ of all TSCC/BOTSCC patients. Uni- and multi-variate analyses for OS and DFS were performed for HPVDNA ${ }^{+/-}$/ $\mathrm{p} 16^{+/-}$status, age, dichotomized smoking status (Ever vs. Never), and dichotomized TNM-7 stage (1-2 vs. 3-4) (Table 2).

Table 2. Uni- and multivariable analysis of OS and DFS in patients with TSCC/BOTSCC and PS 0.

\begin{tabular}{|c|c|c|c|c|c|c|c|c|c|c|c|c|c|}
\hline & & \multicolumn{6}{|c|}{ Overall Survival (OS) } & \multicolumn{6}{|c|}{ Disease-Free Survival (DFS) } \\
\hline & & HR & $\begin{array}{l}\text { Univariable } \\
95 \% \text { CI }\end{array}$ & $p$-Value & HR & $\begin{array}{l}\text { Multivariable } \\
95 \% \text { CI }\end{array}$ & $p$-Value & HR & $\begin{array}{l}\text { Univariable } \\
95 \% \mathrm{CI}\end{array}$ & $p$ & HR & $\begin{array}{c}\text { Multivariable } \\
95 \% \mathrm{CI}\end{array}$ & $p$ \\
\hline \multirow{3}{*}{$\mathrm{HPV} / \mathrm{p} 16$ status } & HPV-p16- & 1 & & & 1 & & & 1 & & & 1 & & \\
\hline & HPV-p16+ & 0.31 & $0.15-0.66$ & 0.002 & 0.49 & $0.23-1.05$ & 0.07 & 0.34 & $0.12-0.98$ & 0.05 & 0.43 & $0.15-1.3$ & 0.1 \\
\hline & $\mathrm{HPV}+\mathrm{p} 16+$ & 0.23 & $0.17-0.34$ & $<0.0001$ & 0.30 & $0.21-0.44$ & $<0.0001$ & 0.25 & $0.15-0.42$ & $<0.0001$ & 0.29 & $0.17-0.50$ & $<0.0001$ \\
\hline \multirow{2}{*}{ Age } & & 1.06 & $1.05-1.09$ & $<0.0001$ & 1.1 & $1.04-1.08$ & $<0.0001$ & 1.04 & $1.02-1.06$ & 0.001 & 1.03 & $1.008-1.06$ & 0.009 \\
\hline & Ever & 1 & & & 1 & & & 1 & & & 1 & & \\
\hline Smoking & Never & 0.46 & $0.30-0.68$ & $<0.0001$ & 0.58 & $0.38-0.88$ & 0.01 & 0.54 & $0.31-0.93$ & 0.03 & 0.69 & $0.39-1.3$ & 0.2 \\
\hline \multirow{2}{*}{ Stage (TNM-7) } & I/II & 1 & & & 1 & & & 1 & & & 1 & & \\
\hline & $\mathrm{III} / \mathrm{IV}$ & 1.12 & $0.66-1.9$ & 0.7 & 1.6 & $0.93-2.8$ & 0.09 & 1.36 & $0.59-3.1$ & 0.5 & 1.8 & $0.78-4.3$ & 0.2 \\
\hline
\end{tabular}

Notably, patients with HPVDNA ${ }^{+/}$p $16^{+}$TSCC/BOTSCC had a clearly better OS and DFS than those with HPVDNA ${ }^{-} / \mathrm{p}^{1} 6^{-}$TSCC/BOTSCC, both in the uni- and in the multivariate analysis, while those with $\mathrm{HPVDNA}^{-} / \mathrm{p} 16^{+} \mathrm{TSCC} / \mathrm{BOTSCC}^{-}$only had a significantly better OS compared to those with HPVDNA ${ }^{-} / \mathrm{p}^{-} 6^{-}$cancer in the univariate analysis (Table 2). Moreover, irrespective of HPVDNA and p16, age was also significantly correlated to both OS and DFS in the univariate and multivariate analysis. For the dichotomized stage (1-2 vs. 3-4), no significant differences were observed for either OS or DFS (Table 2). 


\subsection{Survival after Recurrence TSCC/BOTSCC in Relation to HPV and Overexpression of $p 16$}

Survival after recurrence (LRR or DR) in patients with TSCC/BOTSCC was also assessed in correlation to HPVDNA ${ }^{+/-}$and $\mathrm{p}^{+6^{+/-}}$status. Survival was generally low (5.9\%) after LRR/DR and did not differ significantly between patients with $\mathrm{HPVDNA}^{+} / \mathrm{p}^{+} 6^{+}$, $\mathrm{HPVDNA}^{-} / \mathrm{p}^{-} 6^{-}$, and HPVDNA ${ }^{-} / \mathrm{p} 16^{+}$TSCC /BOTSCC (Figure 5).

\section{TSCC and BOTSCC}

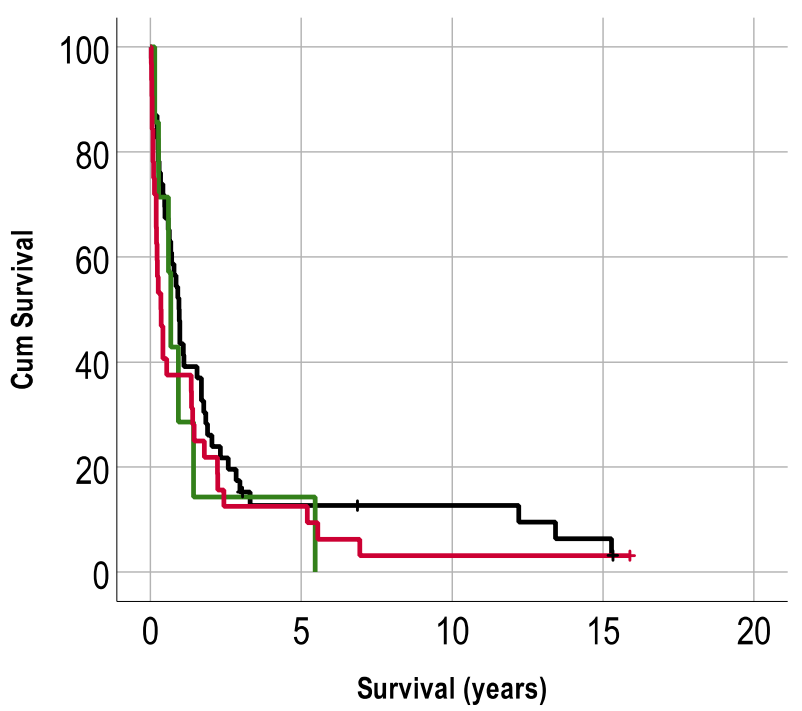

\section{HPV and p16 status}

$\Omega H P V+p 16+$

$\Omega H P V-p 16+$

$\Omega H P V-p 16-$

+-censored

+-censored

+-censored

Figure 5. Kaplan-Meier figures with survival after a loco-regional or distant recurrence (LRR/DR) separated for HPV and p16 status. No significant differences were observed in survival between patients with TSCC/BOTSCC after recurrent disease independent of HPV and p16 status. (HPV+p16+ vs. HPV - p16- (log rank test): $p=0.17)$.

\section{Discussion}

In this large, long term follow-up cohort study of OPSCC and its subsites, we disclosed that $\mathrm{p} 16^{+}$was correlated to a favorable OS and DFS in patients with TSCC/BOTSCC as compared to those with corresponding $\mathrm{p} 16^{-}$cancer, while in patients with otherOPSCC, no such analogy was observed. Likewise, patients with $\mathrm{HPVDNA}^{+} / \mathrm{p} 16^{+} \mathrm{TSCC} / \mathrm{BOTSCC}$ presented a better OS and DFS compared to those with $\mathrm{HPVDNA}^{-} / \mathrm{p}^{-} 6^{-}$tumors, while notably, those with HPVDNA ${ }^{-} / \mathrm{p}^{1} 6^{+}$carcinomas presented an intermediate survival. Finally, late recurrences were rare, but were significantly more frequent in patients with p16- tumors, but nevertheless, the prognosis for recurrent disease was poor independent of the HPVDNA ${ }^{+/-} / \mathrm{p} 16^{+/-}$status of the tumor.

Consequently, in this report, we confirm previous results by ourselves and others that patient and tumor characteristics differ significantly between OPSCC arising in a lymphoepithelial context (TSCC/BOTSCC) and those arising in a non-lymphoepithelial context (otherOPSCC) [17-24]. In a previous study, we found that p16-status was poorly correlated to 5-year OS and DFS in patients with otherOPSCC, and that $\mathrm{p} 16^{+}$was not a reliable surrogate marker for active HPV infection in this tumor type [32]. In addition, we have earlier shown that patients with $\mathrm{p} 16^{+}$otherOPSCC at a low stage have a significantly worse OS compared to patients with TSCC/BOTSCC at the same stage [18]. Taken together, the data suggest that survival and pattern of recurrence for $\mathrm{p} 16^{+}$otherOPSCC, instead resembles $\mathrm{p} 16^{-}$TSCC/BOTSCC/otherOPSCC. Consequently, p16 ${ }^{+}$status is not suitable to determine stage or choices of treatment in patients with otherOPSCC.

In addition, we also demonstrated in a subgroup analysis of TSCC/BOTSCC patients that patients with discordant $\left(\mathrm{HPVDNA}^{-} / \mathrm{p}^{+} 6^{+}\right.$) have a worse survival, compared to those with $\mathrm{HPVDNA}^{+} / \mathrm{p} 16^{+}$TSCC/BOTSCC. Moreover, patients with discordant HPV and p16 
status had a more ambiguous survival benefit over patients with $\mathrm{HPVDNA}^{-} / \mathrm{p}^{-} 6^{-}$cancer, compared to those with HPVDNA ${ }^{+} / \mathrm{p} 16^{+} \mathrm{TSCC} /$ BOTSCC. Our data imply that there may be a risk of future undertreatment of patients with $\mathrm{HPVDNA}^{-} / \mathrm{p}^{-} 6^{+}$tumors, and possibly the opposite upon treatment of patients with $\mathrm{HPVDNA}^{+} / \mathrm{p}^{-} 6^{-}$tumors when patients are classified only based on $\mathrm{p} 16^{+/-}$status with the new TNM- 8 staging system. These data suggest that the prognostic value of p16 is inferior to the combination of p16 and HPVDNA [13].

Although the above data need to be confirmed, they still suggest that some caution is necessary when conducting novel treatment strategies based on the new TNM-8 staging system [20].

Finally, we could not confirm earlier findings from smaller studies that patients with p16 $16^{+}$TSCC/BOTSCC have a higher incidence of late relapses compared to patients with p16- TSCC/BOTSCC [32,33]. In general, only few cases relapsed after 5 years, and these tended to originate from $\mathrm{p} 16^{-}$tumors. In addition, we did not observe any difference in survival between patients with $\mathrm{p} 16^{+}$and $\mathrm{p} 16^{-}$TSCC/BOTSCC-patients upon recurrence, which also differs from some earlier reports [34,35].

Of note, in most countries, the current first line of treatment in OPSCC is radiotherapy or chemoradiotherapy, with fairly good results in patients with $\mathrm{p} 16^{+} \mathrm{TSCC} / \mathrm{BOTSCC}$, but with less favorable outcome in patients with $\mathrm{p} 16^{-}$TSCC/BOTSCC and with otherOPSCC, regardless of $\mathrm{p} 16$ status. This calls for further studies on how to improve survival for patients with $\mathrm{p} 16^{-}$TSCC/BOTSCC. As for otherOPSCC, it is not unlikely that the tumors within this group may better resemble oral cancer and benefit from primary surgery regardless of $\mathrm{p} 6^{+/-}$status. In fact, one report demonstrated better recurrence free survival in patients with $\mathrm{p} 16^{-}$OPSCC when they were treated with upfront surgery instead of radiotherapy and chemotherapy; however, surgery did not have an impact on OS [36].

This study has several limitations. Firstly, although the study population is relatively large, it is a retrospective single-center study with clinical data collected prospectively from patients' records. Secondly, we have not adjusted data for treatment modalities or for changes in treatment regimens over time. However, at our center, treatment has been consistent within and between the subsites over time, irrespective of $\mathrm{p} 16^{+/-}$and $\mathrm{HPVDNA}^{+/-}$status, implying accuracy in the results. Finally, the group of otherOPSCC was relatively small, resulting in limited numbers of $\mathrm{p} 16^{+}$tumors in that group. To confirm our findings, we encourage larger multicenter studies.

\section{Conclusions}

In conclusion, this study of long-term outcome and recurrence shows that patients with $\mathrm{p} 16^{+}$TSCC/BOTSCC have better long-term OS and DFS than patients with corresponding $\mathrm{p} 16^{-}$cancer. However, the combination of HPVDNA ${ }^{+}$and $\mathrm{p}^{16^{+}}$status presented more accurate and detailed prognostic information than $\mathrm{p}^{16^{+/-}}$status alone in patients with TSCC/BOTSCC. We therefore recommend the use of combined HPVDNA ${ }^{+} / \mathrm{p}^{+} 6^{+}$ analysis for TSCC/BOTSCC when conducting treatment decisions and future tailored trials. In addition, importantly, $\mathrm{p} 16^{+}$status did not affect long-term outcome in patients with otherOPSCC. However, larger studies will be required to confirm these results. Finally, late recurrences were rare in OPSCC, and patients with $16^{+}$TSCC/BOTSCC did not have a higher frequency of late metastasis compared to those with corresponding $\mathrm{p} 16^{-}$ carcinomas, nor did $\mathrm{p} 16^{+}$status in their carcinomas affect outcome after recurrence.

Author Contributions: Conceptualization, M.W., L.H.-N., S.F., E.M.-W., T.D., A.N. and L.M.; methodology, M.W., L.H.-N., T.D., A.N. and L.M.; software, A.N.; validation, M.W., L.H.-N., M.Z., D.L., A.N. and L.M.; formal analysis, M.W., L.H.-N., A.N. and L.M.; investigation, M.W., D.L. and M.Z.; resources, E.M.-W., T.D. and A.N.; data curation, M.W., L.H.-N., M.Z., D.L. and L.M.; writing-original draft preparation, M.W., A.N. and L.M.; writing-review and editing M.W., L.H.-N., M.Z., S.F., D.L., E.M.-W., T.D., A.N. and L.M.; visualization, M.W., A.N. and L.M.; supervision, T.D., A.N. and L.M.; project administration, T.D., A.N. and L.M.; funding acquisition, T.D., L.M. and A.N. All authors have read and agreed to the published version of the manuscript. 
Funding: This research was funded by THE SWEDISH CANCER SOCIETY, grant numbers 200778P, 200704P, 200764Fk, and 210292JCIA; STOCKHOLMS LÄNS LANDSTING (ALF), grant number 20200059; THE CANCER AND ALLERGY FOUNDATION, grant numbers 10127 and 10137; MAGNUS BERGVALLS STIFTELSE, grant number 2020-03737; TORNSPIRAN, grant number 2020; THE STOCKHOLM CANCER SOCIETY, grant numbers 201242 and 201092; and SVENSKA LÄKARESÄLLSKAPET, grant number SLS-935256.

Institutional Review Board Statement: The study was conducted according to the guidelines of the Declaration of Helsinki and approved by the Institutional Review Board of Karolinska Institutet (2005/431-31/4; 2009/1278-31/4; 2017/1035-31/2).

Informed Consent Statement: Informed consent was obtained from all subjects involved in the study according to the ethical permissions stated above.

Data Availability Statement: The data presented in this study are available on request from the corresponding author. The data are not publicly available due to Swedish laws on personal confidential information.

Conflicts of Interest: The authors declare no conflict of interest.

\section{References}

1. Syrjänen, K.J.; Syrjänen, S.M.; Lamberg, M.A.; Pyrhönen, S. Human papillomavirus (HPV) involvement in squamous cell lesions of the oral cavity. Proc. Finn. Dent. Soc. 1983, 79, 1-8.

2. Chaturvedi, A.K.; Engels, E.A.; Pfeiffer, R.M.; Hernandez, B.Y.; Xiao, W.; Kim, E.; Jiang, B.; Goodman, M.T.; Sibug-Saber, M.; Cozen, W.; et al. Human papillomavirus and rising oropharyngeal cancer incidence in the United States. J. Clin. Oncol. 2011, 29, 4294-4301. [CrossRef] [PubMed]

3. Marklund, L.; Hammarstedt, L. Impact of HPV in Oropharyngeal Cancer. J. Oncol. 2011, 2011, 509036. [CrossRef]

4. Mork, J.; Lie, A.K.; Glattre, E.; Hallmans, G.; Jellum, E.; Koskela, P.; Møller, B.; Pukkala, E.; Schiller, J.T.; Youngman, L.; et al. Human papillomavirus infection as a risk factor for squamous-cell carcinoma of the head and neck. N. Engl. J. Med. 2001, 344, 1125-1131. [CrossRef] [PubMed]

5. Nasman, A.; Attner, P.; Hammarstedt, L.; Du, J.; Eriksson, M.; Giraud, G.; Ahrlund-Richter, S.; Marklund, L.; Romanitan, M.; Lindquist, D.; et al. Incidence of human papillomavirus (HPV) positive tonsillar carcinoma in Stockholm, Sweden: An epidemic of viral-induced carcinoma? Int. J. Cancer 2009, 125, 362-366. [CrossRef]

6. Dahlgren, L.; Dahlstrand, H.M.; Lindquist, D.; Hogmo, A.; Bjornestal, L.; Lindholm, J.; Lundberg, B.; Dalianis, T.; Munck-Wikland, E. Human papillomavirus is more common in base of tongue than in mobile tongue cancer and is a favorable prognostic factor in base of tongue cancer patients. Int. J. Cancer 2004, 112, 1015-1019. [CrossRef]

7. Rietbergen, M.M.; Leemans, C.R.; Bloemena, E.; Heideman, D.A.; Braakhuis, B.J.; Hesselink, A.T.; Witte, B.I.; de Jong, R.J.B.; Meijer, C.J.; Snijders, P.J.; et al. Increasing prevalence rates of HPV attributable oropharyngeal squamous cell carcinomas in the Netherlands as assessed by a validated test algorithm. Int. J. Cancer 2013, 132, 1565-1571. [CrossRef]

8. Fakhry, C.; Westra, W.H.; Li, S.; Cmelak, A.; Ridge, J.A.; Pinto, H.; Forastiere, A.; Gillison, M.L. Improved survival of patients with human papillomavirus-positive head and neck squamous cell carcinoma in a prospective clinical trial. J. Natl. Cancer Inst. 2008, 100, 261-269. [CrossRef]

9. Dahlstrand, H.; Näsman, A.; Romanitan, M.; Lindquist, D.; Ramqvist, T.; Dalianis, T. Human papillomavirus accounts both for increased incidence and better prognosis in tonsillar cancer. Anticancer Res. 2008, 28, 1133-1138.

10. Nygård, M.; Aagnes, B.; Bray, F.; Møller, B.; Mork, J. Population-based evidence of increased survival in human papillomavirusrelated head and neck cancer. Eur. J. Cancer 2012, 48, 1341-1346. [CrossRef]

11. Sturgis, E.M.; Cinciripini, P.M. Trends in head and neck cancer incidence in relation to smoking prevalence: An emerging epidemic of human papillomavirus-associated cancers? Cancer 2007, 110, 1429-1435. [CrossRef] [PubMed]

12. Marur, S.; D'Souza, G.; Westra, W.H.; Forastiere, A.A. HPV-associated head and neck cancer: A virus-related cancer epidemic. Lancet Oncol. 2010, 11, 781-789. [CrossRef]

13. Smeets, S.J.; Hesselink, A.T.; Speel, E.J.; Haesevoets, A.; Snijders, P.J.; Pawlita, M.; Meijer, C.J.; Braakhuis, B.J.; Leemans, C.R.; Brakenhoff, R.H. A novel algorithm for reliable detection of human papillomavirus in paraffin embedded head and neck cancer specimen. Int. J. Cancer 2007, 121, 2465-2472. [CrossRef] [PubMed]

14. Wagner, S.; Prigge, E.S.; Wuerdemann, N.; Reder, H.; Bushnak, A.; Sharma, S.J.; Obermueller, T.; von Knebel Doeberitz, M.; Dreyer, T.; Gattenlöhner, S.; et al. Evaluation of p16(INK4a) expression as a single marker to select patients with HPV-driven oropharyngeal cancers for treatment de-escalation. Br. J. Cancer 2020, 123, 1114-1122. [CrossRef]

15. Dahlstrand, H.M.; Lindquist, D.; Björnestål, L.; Ohlsson, A.; Dalianis, T.; Munck-Wikland, E.; Elmberger, G. P16(INK4a) correlates to human papillomavirus presence, response to radiotherapy and clinical outcome in tonsillar carcinoma. Anticancer Res. 2005, $25,4375-4383$.

16. Amin, M.B.; Edge, S.B.; Greene, F.; Byrd, D.R.; Brookland, R.K.; Washington, M.K.; Gershenwald, J.E.; Compton, C.C.; Hess, K.R.; Sullivan, D.C.; et al. AJCC Cancer Staging Manual, 8th ed.; Springer: Chicago, IL, USA, 2017. 
17. Haeggblom, L.; Ramqvist, T.; Tommasino, M.; Dalianis, T.; Nasman, A. Time to change perspectives on HPV in oropharyngeal cancer. A systematic review of HPV prevalence per oropharyngeal sub-site the last 3 years. Papillomavirus Res. 2017, 4, 1-11. [CrossRef]

18. Marklund, L.; Holzhauser, S.; de Flon, C.; Zupancic, M.; Landin, D.; Kolev, A.; Haeggblom, L.; Munck-Wikland, E.; HammarstedtNordenvall, L.; Dalianis, T.; et al. Survival of patients with oropharyngeal squamous cell carcinomas (OPSCC) in relation to TNM 8-Risk of incorrect downstaging of HPV-mediated non-tonsillar, non-base of tongue carcinomas. Eur. J. Cancer 2020, 139, 192-200. [CrossRef]

19. Hammarstedt, L.; Holzhauser, S.; Zupancic, M.; Kapoulitsa, F.; Ursu, R.G.; Ramqvist, T.; Haeggblom, L.; Näsman, A.; Dalianis, T.; Marklund, L. The value of p16 and HPV DNA in non-tonsillar, non-base of tongue oropharyngeal cancer. Acta Otolaryngol. 2021, 141, 89-94. [CrossRef]

20. Tham, T.; Wotman, M.; Roche, A.; Kraus, D.; Costantino, P. The prognostic effect of anatomic subsite in HPV-positive oropharyngeal squamous cell carcinoma. Am. J. Otolaryngol. 2019, 40, 567-572. [CrossRef]

21. Gelwan, E.; Malm, I.J.; Khararjian, A.; Fakhry, C.; Bishop, J.A.; Westra, W.H. Nonuniform Distribution of High-risk Human Papillomavirus in Squamous Cell Carcinomas of the Oropharynx: Rethinking the Anatomic Boundaries of Oral and Oropharyngeal Carcinoma from an Oncologic HPV Perspective. Am. J. Surg. Pathol. 2017, 41, 1722-1728. [CrossRef]

22. Ljokjel, B.; Lybak, S.; Haave, H.; Olofsson, J.; Vintermyr, O.K.; Aarstad, H.J. The impact of HPV infection on survival in a geographically defined cohort of oropharynx squamous cell carcinoma (OPSCC) patients in whom surgical treatment has been one main treatment. Acta Otolaryngol. 2014, 134, 636-645. [CrossRef] [PubMed]

23. Garnaes, E.; Kiss, K.; Andersen, L.; Therkildsen, M.H.; Franzmann, M.B.; Filtenborg-Barnkob, B.; Hoegdall, E.; Krenk, L.; Josiassen, M.; Lajer, C.B.; et al. A high and increasing HPV prevalence in tonsillar cancers in Eastern Denmark, 2000-2010: The largest registry-based study to date. Int. J. Cancer 2015, 136, 2196-2203. [CrossRef] [PubMed]

24. Haeggblom, L.; Attoff, T.; Hammarstedt-Nordenvall, L.; Nasman, A. Human papillomavirus and survival of patients per histological subsite of tonsillar squamous cell carcinoma. Cancer Med. 2018, 7, 1717-1722. [CrossRef] [PubMed]

25. Gillison, M.L.; Trotti, A.M.; Harris, J.; Eisbruch, A.; Harari, P.M.; Adelstein, D.J.; Jordan, R.C.K.; Zhao, W.; Sturgis, E.M.; Burtness, B.; et al. Radiotherapy plus cetuximab or cisplatin in human papillomavirus-positive oropharyngeal cancer (NRG Oncology RTOG 1016): A randomised, multicentre, non-inferiority trial. Lancet 2019, 393, 40-50. [CrossRef]

26. Christopherson, K.M.; Moreno, A.C.; Elgohari, B.; Gross, N.; Ferrarotto, R.; Mohamed, A.S.R.; Gunn, G.B.; Goepfert, R.P.; Mott, F.E.; Shah, S.J.; et al. Outcomes after salvage for HPV-positive recurrent oropharyngeal cancer treated with primary radiation. Oral Oncol. 2020, 113, 105125. [CrossRef] [PubMed]

27. Trosman, S.J.; Koyfman, S.A.; Ward, M.C.; Al-Khudari, S.; Nwizu, T.; Greskovich, J.F.; Lamarre, E.D.; Scharpf, J.; Khan, M.J.; Lorenz, R.R.; et al. Effect of human papillomavirus on patterns of distant metastatic failure in oropharyngeal squamous cell carcinoma treated with chemoradiotherapy. JAMA Otolaryngol. Head Neck Surg. 2015, 141, 457-462. [CrossRef]

28. Huang, S.H.; Perez-Ordonez, B.; Weinreb, I.; Hope, A.; Massey, C.; Waldron, J.N.; Kim, J.; Bayley, A.J.; Cummings, B.; Cho, B.C.; et al. Natural course of distant metastases following radiotherapy or chemoradiotherapy in HPV-related oropharyngeal cancer. Oral Oncol. 2013, 49, 79-85. [CrossRef]

29. Guo, T.; Rettig, E.; Fakhry, C. Understanding the impact of survival and human papillomavirus tumor status on timing of recurrence in oropharyngeal squamous cell carcinoma. Oral Oncol. 2016, 52, 97-103. [CrossRef]

30. O'Sullivan, B.; Adelstein, D.L.; Huang, S.H.; Koyfman, S.A.; Thorstad, W.; Hope, A.J.; Lewis, J.S., Jr.; Nussenbaum, B. First Site of Failure Analysis Incompletely Addresses Issues of Late and Unexpected Metastases in p16-Positive Oropharyngeal Cancer. J. Clin. Oncol. 2015, 33, 1707-1708. [CrossRef]

31. Nasman, A.; Nordfors, C.; Holzhauser, S.; Vlastos, A.; Tertipis, N.; Hammar, U.; Hammarstedt-Nordenvall, L.; Marklund, L.; Munck-Wikland, E.; Ramqvist, T.; et al. Incidence of human papillomavirus positive tonsillar and base of tongue carcinoma: A stabilisation of an epidemic of viral induced carcinoma? Eur. J. Cancer 2015, 51, 55-61. [CrossRef]

32. Marklund, L.; Näsman, A.; Ramqvist, T.; Dalianis, T.; Munck-Wikland, E.; Hammarstedt, L. Prevalence of human papillomavirus and survival in oropharyngeal cancer other than tonsil or base of tongue cancer. Cancer Med. 2012, 1, 82-88. [CrossRef] [PubMed]

33. Lewis, J.S., Jr.; Beadle, B.; Bishop, J.A.; Chernock, R.D.; Colasacco, C.; Lacchetti, C.; Moncur, J.T.; Rocco, J.W.; Schwartz, M.R.; Seethala, R.R.; et al. Human Papillomavirus Testing in Head and Neck Carcinomas: Guideline from the College of American Pathologists. Arch. Pathol. Lab. Med. 2018, 142, 559-597. [CrossRef] [PubMed]

34. Fakhry, C.; Zhang, Q.; Nguyen-Tan, P.F.; Rosenthal, D.; El-Naggar, A.; Garden, A.S.; Soulieres, D.; Trotti, A.; Avizonis, V.; Ridge, J.A.; et al. Human papillomavirus and overall survival after progression of oropharyngeal squamous cell carcinoma. J. Clin. Oncol. 2014, 32, 3365-3373. [CrossRef] [PubMed]

35. Argiris, A.; Li, S.; Ghebremichael, M.; Egloff, A.M.; Wang, L.; Forastiere, A.A.; Burtness, B.; Mehra, R. Prognostic significance of human papillomavirus in recurrent or metastatic head and neck cancer: An analysis of Eastern Cooperative Oncology Group trials. Ann. Oncol. 2014, 25, 1410-1416. [CrossRef] [PubMed]

36. Culié, D.; Viotti, J.; Modesto, A.; Schiappa, R.; Chamorey, E.; Dassonville, O.; Poissonnet, G.; Guelfucci, B.; Bizeau, A.; Vergez, S.; et al. Upfront surgery or definitive radiotherapy for patients with p16-negative oropharyngeal squamous cell carcinoma. A GETTEC multicentric study. Eur. J. Surg. Oncol. 2021, 47, 367-374. [CrossRef] 